\title{
Ensaios Clínicos: História e Atualidade
}

\section{Clinical Trials: History and Actuality}

António Vasco Salgado ${ }^{1}$

PALAVRAS-CHAVE: Ensaios Clínicos/história

KEYWORDS: Clinical Trials/history

Embora haja referências prévias na Bíblia, no Cânone de Medicina de Avicenna e na obra do médico-cirurgião francês Ambroise Parré datada de 1537, considera-se que o primeiro ensaio clínico da era moderna foi realizado por James Lind em 1747, quando foi descoberto o efeito terapêutico do consumo de citrinos no tratamento do escorbuto.

Passados cerca de cem anos, em 1863, Austin Flint realizou o primeiro ensaio com um grupo placebo em doentes com reumatismo.

Em 1943 surge pela primeira vez um estudo duplamente cego com aleatorização alternada em doentes com síndrome gripal.

Três anos depois é realizado o primeiro ensaio com processo de aleatorização, tal como definido hoje em dia, com dupla ocultação em doentes com tuberculose, em que o efeito da estreptomicina foi comparado com tratamento de repouso apenas. Trata-se também do primeiro ensaio em que a avaliação dos "endpoints", neste caso o resultado da radiografia do tórax foi avaliado, por médicos independentes, que desconheciam o braço a que pertenciam os doentes.

Foi na segunda metade do século XX, sobretudo no rescaldo da II Guerra Mundial, que a maioria dos avanços de natureza ética na condução de ensaios clínicos foram realizados, tendo em vista a proteção dos indivíduos que participavam em ensaios clínicos.

Em 1947 o código de Nuremberga estipula a necessidade de participação voluntária e da necessidade de existência de consentimento informado. Quase em simultâneo, em 1948, a Declaração dos Direitos Humanos, proíbe a participação de seres humanos em tratamentos considerados prejudiciais.

Nos anos sessenta, na sequência dos casos de malformações associados ao uso da talidomida, surgem as primeiras iniciativas governamentais, através das Agências do 
Medicamento, nomeadamente a Food and Drug Administration, no controlo da realização dos ensaios clínicos.

Finalmente em 1996 é publicada a Declaração de Helsínquia que estipula os princípios gerais na realização dos ensaios clínicos. Esta declaração que tem sido revista desde então, veio a incluir um aspeto fundamental na realização dos ensaios, nomeadamente o conceito de boas práticas clínicas.

Desenvolvimentos mais recentes, têm incluído a obrigatoriedade dos Investigadores terem certificação nas ferramentas de medida utilizadas, bem como em alguns casos a necessidade da existência de avaliadores independentes, do Investigador Principal e Co-Investigadores que conduzem o ensaio. Da mesma forma muitos ensaios clínicos utilizam Centros que reúnem toda a avaliação a nível global, para leitura e avaliação sistematizada dos resultados. Igualmente, para assegurar a segurança dos participantes e resolver questões de natureza ética, a existência de Comités Independentes de Monitorização de Segurança, é uma obrigatoriedade desde há vários anos.

Outro dos desenvolvimentos dos últimos anos prende-se com novas ferramentas estatísticas que vieram aumentar a robustez dos resultados obtidos, evitar análises fúteis e enviesamento dos resultados, evitando conclusões espúrias.

Os ensaios clínicos fazem parte da investigação clínica e constituem um aspeto fundamental no avanço da Medicina, sendo o seu principal objetivo determinar se um novo tratamento é eficaz e seguro.

Para tal, os ensaios clínicos passam por várias fases:

FASE I. O tratamento é testado num grupo relativamente reduzido de voluntários tipicamente saudáveis, para testar segurança, efeitos acessórios e várias variáveis biológicas, nomeadamente da biodisponibilidade de fármacos.

FASE II. O tratamento é testado num grupo maior de indivíduos, portadores da doença em que o tratamento está a ser avaliado, tipicamente durante um período de tempo reduzido, para determinar aspetos de natureza fármaco-biológica, variáveis imagiológicas ou outras, efeitos acessórios e segurança. É tipicamente durante esta fase que são testadas várias doses de fármaco para determinar a melhor relação eficácia-segurança. Embora o tema seja por vezes polémico, vários ensaios utilizam nesta fase como comparador um grupo placebo.
FASE III. São realizados num número significativamente maior de doentes, nalguns casos atingindo as dezenas de milhar, durante um período de tempo significativamente superior, para comparar a eficácia e natureza dos efeitos secundários, com tratamento standard ou equivalente e que permita colecionar informação que permita utilizar o tratamento experimental, de forma segura na patologia que está a ser avaliada. De uma forma geral, as Agências do Medicamento só autorizam a existência de um grupo placebo, nesta fase, para doenças que não tenham qualquer tratamento com eficácia comprovada.

FASE IV. Trata-se de estudos de segurança realizados após a aprovação pelas Agências da Medicação, para avaliar riscos, benefícios e melhor paradigma de utilização no mundo real.

Do ponto de vista dos doentes, a participação em ensaios clínicos permite o acesso a tratamentos inovadores e potencialmente mais eficazes para doenças em que já haja tratamentos aprovados e sobretudo em doenças sem tratamentos aprovados ou com terapêuticas pouco eficazes.

Do ponto de vista institucional, a participação em ensaios clínicos tem permitido uma certa partilha dos custos dos tratamentos e constitui talvez uma das formas mais pedagógicas no treino de jovens médicos pela exigência de rigor na avaliação de diferentes patologias.

Os ensaios clínicos constituem uma das melhores parcerias entre a Indústria e a Academia, uma vez que têm sido os académicos a desenhar e conduzir os mesmos. Por outro lado, têm permitido colecionar uma quantidade de informação, que devidamente trabalhada possibilita responder a questões científicas, que de outra forma não seria possível.

CONFLITOS DE INTERESSE: Os autores declaram a inexistência de conflitos de interesse na realização do trabalho.

FONTES DE FINANCIAMENTO: Não existiram fontes externas de financiamento para a realização deste artigo. 